\section{Infantile hypertrophic pyloric stenosis}

Sir,

The nice summary article of 'Infantile hypertrophic pyloric stenosis in Belfast, 1957-1969' by J. A Dodge (Archives, 1975, 50, 171) refers in part to jaundice noted in $1.8 \%$ of such patients before operation. In hypothesizing on the subject he fails to mention my favourite thesis, which is that such jaundiced infants have a fairly marked alkalosis and it is this alkalosis which inhibits the activity of the glucuronyl transferase. On occasion there have been infants seen who, on rehydration, clinically seem to clear their jaundice. Unfortunately the definitive study of doing a bilirubin before hydration and correction of alkalosis and then after (but before operation) has not been done. Perhaps Dr. Dodge might comment.

\section{WILLIAM D. COCHRAN Harvard Medical School, Joint Program in Neonatology, 221 Longwood Ave. Boston, Mass. 02115, U.S.A.}

Dr. Dodge comments as follows:

I was interested to read Dr. Cochran's kind comments on my article, and in particular his views on the occurrence of jaundice in infantile pyloric stenosis, and apologize for overlooking the possibility that alkalosis may be a contributory factor.

There is no doubt that correction of metabolic ababnormalities is an important factor in the resolution of jaundice in these babies, but there is no good evidence that it is the restoration of fluid or of acid-base balance which effects the response. Thus, in the only one of my 12 jaundiced patients with really adequate biochemical documentation, there was no clinical evidence of dehydration and his plasma bicarbonate was $24 \mathrm{mEq} / 1$ on admission and rose to $30.6 \mathrm{mEq} / \mathrm{l}$ on the day of operation ( 3 days later), by which time the jaundice was already fading. I remember attending a C.P.C. in Boston on 29 November 1961, when Dr. Cochran himself discussed a jaundiced 'pyloric'. The patient's bicarbonate level was recorded as $24.8 \mathrm{mEq} / \mathrm{l}$.

It seems to me that the most likely explanation for jaundice is impairment of hepatic glucuronyl transferase activity by reduced caloric intake. This hypothesis has been studied by Felsher et al. (1973), who found depressed activity of the UDPG-transferase system in surgical liver biopsies from jaundiced infants with gastrointestinal obstruction, but a tenfold higher level in nonicteric infants with similar disorders. As I pointed out in my article, the association of jaundice with pyloric stenosis in about $2-3 \%$ of affected infants is of the order expected if the true incidence of Gilbert's disease in the population is as high as the $4 \%$ described by D. Owens (personal communication, 1974) and Kornberg (1942). Improvement after rehydration is therefore attributable to the glucose or other caloric sources in the intravenous fluids.

J. A. DODGE

Department of Child Health, The Welsh National School of Medicine, Heath Park, Cardiff CF4 $4 X W$.

REFERENCES

Felsher, B. F., Asch, M., Carpio, N., and Wooley, M. (1973) Unconjugated hyperbilirubinaemia in neonates with congenital gastrointestinal obstruction. (Asbt.) Gastroenterology, 64, 151.

Kornberg, A. (1942). Latent liver disease in persons recovered from catarrhal jaundice and in otherwise normal medical students as revealed by the bilirubin excretion test. Fournal of Clinical Investigation, 21, 299.

\section{Maternal protein depletion in small-for-gestational-age babies}

Sir,

We are interested in the findings of $\mathrm{H}$. Stein (Archives, 1975) as we have a series of unpublished data on work done a few years ago at King Edward VIII Hospital, Durban, South Africa. We were at that time mainly interested in hypoglycaemia in the neonate. In a previous pilot study we found that though the tendency to hypoglycaemia was frequent in the low-birthweight (birthweight $<2.5 \mathrm{~kg}$ ) and the small-for-gestational-age infants, the total prevalence of hypoglycaemia was unaccountably high. We are dealing with a population group whose nutritional status is precarious (Powell, 1958; Stein, 1975). It was thus possible that poor maternal nutrition determined the prevalence of hypoglycaemia and at the same time that of small-for-gestational-age babies.

We studied the possible correlation between maternal serum proteins, neonatal blood glucose levels, and the small-for-gestational-age babies. Group A consisted of 99 newborn babies and their mothers: 27 preterm infants, 27 babies of low birthweight, and 53 small-forgestational-age babies. There was an overlap between categories, some babies being placed in more than one category. Group B consisted of 131 normal term babies and 30 of their mothers acting as controls. Means, standard deviations, and standard errors of the means were calculated for all variables in the babies and their mothers, and a comparison of means was made between the group studied and the controls. 
Our findings were as follows. There was no significant difference in mean blood glucose concentrations between babies in groups $A$ and $B$ on day 0 . There was no significant difference between the two groups in maternal total proteins, nor in any of the serum protein components. The correlation coefficient between maternal total protein levels, albumin, and globulin components in the mothers in groups $A$ and $B$, and blood glucose in their infants showed no significant difference. The correlation coefficient between maternal serum albumin in group $\mathrm{A}$ and the different categories of babies in the same group (i.e. low birthweight, preterm, and small-for-gestational-age) showed no significant difference. Our findings thus differ from those of Stein, though we are dealing with the same type of population.

M. A. PARENT

Department of Paediatrics, Children's Hospital,

P.O. Box 977, Durban, South Africa.

REFERENCES

Powell, S. J. (1958). The serum protein pattern of liver function tests in the Natal African. South African Fournal of Laboratory and Clinical Medicine, 4, 273.

Stein, H. (1975). Maternal protein depletion and small-for-gestational age babies. Archives of Disease in Childhood, 50, 146.

Dr. H. Stein comments as follows:

I read with great interest the letter of Dr. Parent. There are marked differences between his investigations and ours (Archives, 1975). He has principally investigated the contrast in terms of hypoglycaemia and maternal serum protein levels between term infants (group B) and a group of preterm, low-birthweight, and small-for-gestational-age infants (group A). Even in Group A where he contrasts his 3 categories there is only a relatively small percentage of low-birthweight infants (27 out of 99) and it is not clear whether these are preterm or small-for-gestational-age.

We, on the other hand, investigated a group of low-birthweight infants only, but excluded twins, as we had previously shown that these babies contributed significantly to the high incidence of low-birthweight infants seen by us $(26 \%)$ and especially the small-forgestational-age group (Stein and Ellis, 1974); in the present investigation we were looking for additional aetiological factors. Almost all of our cases were preterm (94 out of 103) and the majority were small-forgestational-age.

It appears that the whole emphasis of the investigations was different. It is also not clear whether Dr. Parent excluded twins as we did. Thus while the population groups are similar, the investigations do not appear comparable.

H. STEIN

Department of Paediatrics, Baragwanath Hospital, P.O. Bertsham 2013, Johannesburg, South Africa. REFERENCE

Stein, H., and Ellis, U. (1974). The low birthweight African baby. Archives of Disease in Childhood, 49, 156.

\section{Opsonic defects}

Sir,

The recently described familial opsonic defect by Scott et al. (1975) in the Archives is a beautifully performed study which deserves recognition. The authors have clearly shown a defect in serum opsonic activity throughout four generations of a family. Their suggestion, however, that, 'A diagnosis of Miller's opsonizing defect was confirmed by demonstration of defective opsonization for yeast phagocytosis by her serum and that of her relatives', is a premise with which I do not fully agree.

Most, if not all, opsonic assays depend upon a multiplicity of plasma factors. While Baker's yeast particles are unique in their dependency upon the fifth component of complement (C5) (Miller and Nilsson, 1974), C5 alone is not sufficient for complete opsonization of yeast. In other words, a deficiency in the yeast opsonic assay may reflect any one of a number of factors, including C5. In order to establish a diagnosis of $\mathrm{C} 5$ dysfunction it is therefore necessary to perform appropriate reconstitution experiments using purified human C5 (Miller and Koblenzer, 1972). Illustration of this point is provided by the observations that patients with other opsonic defects, as for example the patient of Alper and Rosen (1975) with hypercatabolism of C3, have abnormal yeast opsonic assays.

I agree that the nature of any defect revealed, solely, by abnormal yeast opsonic activity requires further definition. In the family reported by us, however, substantial evidence has been presented which points to a functional defect of the $\mathrm{C} 5$ molecule as the cause of the opsonic defect (Nilsson, Miller, and Wyman, 1974). The alternate pathway of complement in this family is normal.

The importance of studies such as that of Scott and co-workers is re-emphasized. A number of opsonic defects obviously exist and the full characterization of each should be vigorously pursued. Not only do we learn much of the normal inflammatory response from each of these defects, but the promise of specific therapy by improved characterization of each is great.

MICHAEL E. MILLER Department of Paediatrics, Charles R. Drew Postgraduate Medical School and U.C.L.A. School of Medicine, 1621 E. 120th Street, Los Angeles, California 90059

REFERENCES

Alper, C. A., and Rosen, F. S. (1975). Increased susceptibility to infection in patients with defects affecting C3. Immuno deficiency in Man and Animals, p. 302 . Ed. by R. A. Good and J. Finstad. Sinauer Associates, Sunderland, Mass.

Miller, M. E., and Koblenzer, P. J. (1972). Leiner's disease and deficiency of C5. Fournal of Pediatrics, 80, 879.

Miller, M. E., and Nilsson, U. R. (1974). A major role of the fifth component of complement (C5) in the opsonization of yeast particles. Partial dichotomy of function and immunochemical measurement. Clinical Immunology and Immunopathology, 2 , 246. 